\title{
Flora e estrutura da vegetação arbustivo-arbórea de uma área de caatinga do Seridó, RN, Brasil
}

\author{
Isaac Lucena de Amorim ${ }^{1}$, Everardo V.S.B. Sampaio ${ }^{2,4}$ e Elcida de Lima Araújo ${ }^{3}$
}

Recebido em 26/10/2004. Aceito em 16/02/2005

\begin{abstract}
RESUMO - (Flora e estrutura da vegetação arbustivo-arbórea de uma área de caatinga do Seridó, RN, Brasil). Para testar a hipótese de que a vegetação do Seridó é aberta e de baixo porte, mesmo em local preservado, foi feito o levantamento fitossociológico de uma área na Estação Ecológica do Seridó, Serra Negra do Norte, RN, Brasil. Todas as plantas lenhosas com perímetro do caule a 1,30 m de altura do solo $\geq 3 \mathrm{~cm}$, em 100 parcelas de $10 \times 10 \mathrm{~m}$, foram contadas e tiveram alturas, perímetros do caule e diâmetros das copas medidos e biomassas aéreas estimadas. Foram encontradas 15 espécies, pertencendo a 15 gêneros e 10 famílias, com índice de diversidade de Shannon de 1,94. São números mais baixos que os da maioria de outras áreas de caatinga. Mimosoideae teve o maior número de espécies (três). Todas as variáveis da estrutura da comunidade, exceto densidade (3.250 planta ha ${ }^{-1}$ ) também tiveram valores menores (área basal $6,1 \mathrm{~m}^{2} \mathrm{ha}^{-1}$, altura máxima 9,5 m, diâmetro máximo $37 \mathrm{~cm}$, área de copas $8.723 \mathrm{~m}^{2} \mathrm{ha}^{-1}$ e biomassa $25 \mathrm{mg} \mathrm{ha}^{-1}$ ) que os de outras áreas de caatinga. O pereiro, Aspidosperma pyrifolium Mart., foi a espécie dominante, com cerca de metade dos totais de densidade, áreas basais e de copas e biomassa. Confirma-se que a vegetação lenhosa do Seridó é aberta e de baixo porte, constituindo um tipo de fisionomia de caatinga distinto dos demais.
\end{abstract}

Palavras-chave: Nordeste do Brasil, semi-árido, biomassa, área de copa, área basal

\begin{abstract}
Flora and structure of the tree and shrub vegetation of the caatinga at Seridó, Rio Grande do Norte State, Brazil). A phytosociological survey was conducted at one area belonging to the Seridó Ecological Station to test the hypothesis that the vegetation at the Seridó region is open and low. All woody plants with stem perimeter at breast height $\geq 3 \mathrm{~cm}$ were counted, within 100 plots, $10 \times 10 \mathrm{~m}$, and each one had its height, stem perimeter, and crown projection diameters measured, and its aboveground biomass estimated. Fifteen species were found, belonging to 15 genera and 10 families, with a Shannon diversity index of 1,94. These values are below those of most of caatinga places elsewhere. Mimosoideae was the family with most species (three). All structural variables, except density, $\left(3,250\right.$ plant ha ${ }^{-1}$, basal area $6.1 \mathrm{~m}^{2} \mathrm{ha}^{-1}$, maximum height $9.5 \mathrm{~m}$, maximum stem diameter $37 \mathrm{~cm}$, total crown area $8,723 \mathrm{~m}^{2}$ ha-1, biomass $25 \mathrm{mg} \mathrm{ha}^{-1}$ ) had lower values than caatinga elsewhere. Aspidosperma pyrifolium Mart. was the dominant species comprising about half of total density, basal and crown areas and biomass. The small size of plants and the openness of the vegetation is confirmed, indicating that Seridó has a physiognomic type distinct from other caatinga ones.
\end{abstract}

Key words : Brazilian Northeast, semiarid, biomass, canopy, basal area

\section{Introdução}

A caatinga apresenta grande variação fisionômica, principalmente quanto à densidade e ao porte das plantas. Mudanças em escala local, a poucas dezenas de metros, são facilmente reconhecíveis e geralmente ligadas a uma alteração ambiental claramente identificável. É o caso do maior porte das plantas nos vales e do menor sobre lajedos e solos rasos, em consequiência da maior e menor disponibilidade hídrica. As variações numa escala de regiões, abrangendo milhares de quilômetros quadrados, são mais difíceis de identificar, em virtude dos limites difusos, da causalidade múltipla e da variabilidade local interna a cada uma delas. Apesar desta dificuldade, várias tentativas de identificação de tipos regionais de caatinga têm sido feitas, desde a de Luetzelburg (1922-1923) até a de Andrade-Lima (1981).

Em quase todas estas classificações, a vegetação da região do Seridó, no Rio Grande do Norte, tem sido identificada como um dos tipos de caatinga, as mais das vezes sendo denominada pelo próprio nome da região. Nas classificações, tem sido descrita como uma vegetação aberta, formando parques e facultando o

\footnotetext{
Universidade Federal Rural de Pernambuco, Av. Dom Manoel de Medeiros s/n, CEP 52171-900, Recife, PE, Brasil

2 Universidade Federal de Pernambuco, Departamento de Energia Nuclear, Av. Prof. Luís Freire 1000, CEP 50740-540, Recife, PE, Brasil

3 Universidade Federal Rural de Pernambuco, Departamento de Biologia, Av. Dom Manoel de Medeiros s/n, CEP 52171-900, Recife, PE, Brasil (elcida@ufrpe.br)

4 Autor para correspondência: esampaio@ufpe.br
} 
616 Amorim, Sampaio \& Araújo: Flora e estrutura da vegetação arbustivo-arbórea de uma área de caatinga do Seridó...

trânsito por toda a parte, com o solo coberto de relva áspera (Luetzelburg 1922-1923) e com plantas arbustivas e arbóreas atrofiadas e esparsas (AndradeLima 1981). O porte reduzido e a fisionomia aberta da vegetação tem sido um dos critérios para classificar a região como um dos núcleos de desertificação, embora pouco se tenha feito para distinguir vegetação pobre por degradação antrópica ou por deficiências ambientais naturais (Sampaio et al. 2003).

Nos trabalhos fitossociológicos brasileiros, das variáveis determinadas para lenhosas, a densidade, a altura e a área basal estão ligadas à ocupação do espaço e ao porte das plantas. Entretanto, precisam ser analisadas em conjunto para transmitir a idéia de plantas pequenas com copas deixando espaços abertos ocupados apenas pela vegetação herbácea. Medidas mais diretas seriam a ocupação do espaço pela área de projeção das copas e a biomassa aérea acumulada. São medidas raras em trabalhos brasileiros e quase inexistentes na caatinga. Projeção de copas foi medida em apenas uma área de caatinga, em Petrolina, PE (Albuquerque et al. 1982) e biomassa medida em uma área, em Serra Talhada, PE (Kauffman et al. 1993) e estimada em 16 locais do Seridó, RN (Costa et al. 2002). As pequenas descrições dos 16 locais indicam que tinham grandes diferenças quanto à conservação da vegetação, de caatinga degradada aberta a caatinga preservada densa, com igual variação nas biomassas (2 a $45 \mathrm{mg} \mathrm{ha}^{-1}$ ) e nas densidades de plantas (360 a 4.220 plantas $\mathrm{ha}^{-1}$ ). Como não foi apresentado o histórico de uso dos locais, os valores não podem ser tomados como representativos da vegetação natural da região porque poderiam refletir algum estádio de regeneração após desmatamento total ou parcial. Tem sido mostrado que a vegetação de áreas de caatinga em regeneração tem estrutura diferente da anterior ao desmatamento, mesmo muitos anos depois (Pereira et al. 2003).

Especificamente no Seridó, ainda foram feitos dois trabalhos fitossociológicos: o de Tavares et al. (1975), analisando o potencial madeireiro no vale do Piranhas, e o da tese de doutorado de Ramiro Camacho, defendida na USP em 2001 (informação pessoal), descrevendo a vegetação da Estação Ecológica do Seridó. O primeiro concluiu que a densidade de plantas e o volume de madeira eram baixos (670 plantas ha-1 e $\left.10 \mathrm{~m}^{3} \mathrm{ha}^{-1}\right)$, mas não apresentou descrição clara dos critérios de inclusão de plantas e nem do histórico de uso dos locais amostrados. O segundo (Camacho, informação pessoal), em área bem preservada desde pelo menos 1982, ratificou o pequeno porte das plantas, mas relatou densidades altas. Nos quatro locais amostrados, as alturas máximas variaram de 2,5-7,5 m, as áreas basais de $10-19 \mathrm{~m}^{2} \mathrm{ha}^{-1} \mathrm{e}$ as densidades de 2.800-7.000 plantas ha-1 . Alturas e áreas basais foram mais baixas que as da maioria dos locais de caatinga, enquanto as densidades foram das mais altas (Sampaio 1996). A simples leitura destes dados não transmite a idéia de vegetação aberta que é vista nos diagramas de perfil e nas fotos da tese de Camacho (informação pessoal).

A hipótese resultante dos estudos realizados é de que a região do Seridó caracteriza-se por ser caatinga aberta e de baixo porte. Se isto for verdadeiro, espera-se que a área ocupada pelas copas e a biomassa das plantas tenham valores baixos e não compensatórios da elevada densidade de plantas registrada na região. Este trabalho descreve um levantamento fitossociológico na Estação Ecológica do Seridó, incluindo medidas das copas e estimativa da biomassa aérea, visando caracterizar a ocupação espacial da vegetação e confirmar que o tipo de caatinga do Seridó é distinto dos demais.

\section{Materiais e métodos}

Caracterização da área de estudo - A Estação Ecológica do Seridó (ESEC) localiza-se no Município de Serra Negra do Norte, no sudoeste do Estado do Rio Grande do Norte, entre as coordenadas 06 $35^{\circ}$ e 06 $40^{\prime} \mathrm{S}$ e $37^{\circ} 20^{\prime}$ e $37^{\circ} 39^{\prime} \mathrm{W}$. Criada pelo Decreto Lei N. 87.222, de 31/maio/1982, possui área de 1.166 hectares. O relevo é levemente ondulado, com altitude média de $200 \mathrm{~m}$. Os solos são rasos e pedregosos sobre o embasamento cristalino do pré-cambriano. O solo do local de estudo é um Podzólico Vermelho Amarelo equivalente eutrófico (Ministério da Agricultura 1971), sendo os Podzólicos, pela nova classificação, considerados Argissolos (EMBRAPA 1999).

De acordo com a unidade de observação meteorológica instalada na Estação do Seridó, a temperatura média anual é de $30,7^{\circ} \mathrm{C}$, com a máxima média ocorrendo em outubro $\left(31,0^{\circ} \mathrm{C}\right)$ e a mínima média em fevereiro $\left(29,3^{\circ} \mathrm{C}\right)$. A umidade relativa do ar (UR\%) média é de $50 \%$, sendo, respectivamente, novembro $(43 \%)$ e fevereiro $(62 \%)$ os meses com menor e maior UR\%. O regime de precipitação é de verão - outono com as chuvas concentrando-se entre janeiro e abril. A pluviosidade total varia entre anos (350 a $800 \mathrm{~mm}$ anuais), com média histórica em torno de $600 \mathrm{~mm}$. As chuvas são geralmente torrenciais e as condições de solo raso e pedregoso dificultam a 
retenção de água e favorecem a ocorrência de enxurradas. A velocidade média dos ventos, registrada a $10 \mathrm{~m}$ alt., é de $32,8 \mathrm{~m} \mathrm{~s}^{-1}$, ocorrendo em novembro o maior valor médio $\left(46 \mathrm{~m} \mathrm{~s}^{-1}\right)$ e em maio o menor $\left(2,5 \mathrm{~m} \mathrm{~s}^{-1}\right)$. O clima, pela classificação de Köppen, é Bswh, ou seja, seco, muito quente e com estação chuvosa no verão.

Segundo o Ministério do Meio Ambiente (2004), a Estação do Seridó faz parte de uma área de extrema importância biológica e com informações insuficientes sobre sua flora. Tem um tipo especial de caatinga arbustiva aberta, com baixa riqueza de espécies, predominando uma associação dos gêneros Mimosa, Caesalpinia e Aristida.

Amostragem - Foi realizada numa área de relevo suave-ondulado, coberta por uma vegetação arbóreoarbustiva aberta e fisionomicamente homogênea. Foi feito um inventário sistemático em 100 parcelas contíguas de $10 \times 10 \mathrm{~m}$, em um quadrado de $100 \times 100 \mathrm{~m}$. Todos os indivíduos lenhosos com circunferência do caule a 1,30 m de altura do solo (CAP) superior a três centímetros foram identificados e mensurados. A identificação foi realizada através de morfologia comparada, usando bibliografia especializada e análise das exsicatas do herbário da própria Estação (não cadastrado no Index Herbariorum) e dos Herbários Lauro Pires Xavier (JPB), da Universidade da Paraíba, Professor Vasconcelos Sobrinho (PEUFR), da Universidade Federal Rural de Pernambuco, e Dárdano de Andrade Lima (IPA), da Empresa Pernambucana de Pesquisa Agropecuária. As exsicatas deste levantamento foram depositadas no herbário da Estação e no Lauro Pires Xavier.

Com uma vara graduada, um hipsômetro e uma fita métrica, foram tomadas medidas da altura total da planta, da circunferência do caule a $1,30 \mathrm{~m}$ de altura do solo (CAP) e da largura e comprimento da projeção da copa. A medida do CAP foi transformada em diâmetro (DAP) e em área basal (AB), considerando-se o caule como circular, e as medidas da projeção da copa transformadas em área da copa (AC), considerando que tivesse o formato de elipse. No caso de plantas com caules bifurcados abaixo da altura do peito, com pelo menos uma das ramificações atendendo ao critério de inclusão, foram medidas todas as ramificações, uma a uma. Depois, foram calculadas as áreas basais de cada uma das ramificações e somadas, correspondendo à área basal da planta.

Variáveis calculadas - Seguindo as fórmulas descritas em Mueller-Dombois \& Ellemberg (1974), Rodal et al.
(1992) e Araújo \& Ferraz (2004), foram calculados, para a comunidade geral: a densidade total, a área basal total, a área de copas total e as alturas e diâmetros médios. Para cada espécie foram calculados: densidade, área basal e frequiência e o índice do valor de importância (VI). Também foram calculadas a diversidade de espécies, usando o índice de Shannon, e a riqueza, usando o índice de Whittaker (1975), que é obtido pelo quociente do número de espécies dividido pelo logaritmo natural do número total de plantas. Estes cálculos foram feitos usando o Fitopac 2 (Shepherd 1995).

A biomassa da vegetação não foi determinada diretamente porque não é recomendável desmatar áreas em uma estação ecológica. Ela foi estimada para cada planta amostrada, usando equações alométricas desenvolvidas por Sampaio \& Silva (dados não publicados), com base no diâmetro do caule $\left(\right.$ Biomassa $\left._{\mathrm{kg}}=0,173 \mathrm{DAP}_{\mathrm{cm}}{ }^{2,295}\right)$ e na área do caule e na altura da planta $\left(\right.$ Biomassa $_{\mathrm{kg}}=0,1085\left(\mathrm{AB}_{\mathrm{cm} 2} \times\right.$ $\left.\mathrm{H}_{\mathrm{m}}\right)^{0,9497}$ ). Para plantas bifurcadas, foram usados o DAP médio (que corresponde ao diâmetro da soma das áreas basais de todas as ramificações), a área basal total (soma das áreas basais das ramificações) e a altura total da planta.

Os dados de altura, diâmetro e área de copa foram relacionados entre si, testando-se diferentes modelos de regressão (linear, quadrático, logarítmico, exponencial e potencial) e usando-se programas estatísticos usuais. O ajuste foi avaliado pelo coeficiente de determinação e também pela raiz quadrada do quadrado médio do resíduo, considerando que o número de variáveis e parâmetros era diferente. Apenas as equações com os melhores ajustes são mostradas.

\section{Resultados e discussão}

Riqueza e diversidade florística - Foram medidas 3.247 plantas, pertencentes a 15 espécies, 15 gêneros e 10 famílias (Tab. 1). As famílias com os maiores números de espécies foram Mimosaceae, com três espécies, e Caesalpinaceae e Euphorbiaceae, ambas com duas. Estas três famílias também foram as mais representativas em outros locais da Estação Ecológica do Seridó (Camacho, informação pessoal) e em outras áreas do Rio Grande do Norte (Tavares et al. 1975; Figueiredo 1987). Todos os gêneros foram representados por uma única espécie.

A quantidade de espécies identificadas foi muito pequena, embora maior que a encontrada por Camacho 
618 Amorim, Sampaio \& Araújo: Flora e estrutura da vegetação arbustivo-arbórea de uma área de caatinga do Seridó...

Tabela 1. Listagem das espécies arbóreo-arbustivas (por ordem alfabética de família e nome científico), encontradas em um trecho da Estação Ecológica do Seridó, Serra Negra do Norte, RN, Brasil.

\begin{tabular}{lll}
\hline Família & Nome científico & Nome vulgar \\
\hline Apocynaceae & Aspidosperma pyrifolium Mart. & pereiro \\
Bignoniaceae & Tabebeuia impetiginosa (Mart. ex DC.) Standl. & pau-d'arco-roxo \\
Boraginaceae & Cordia globosa (Jacq.) Humb., Bompl. \& Kunth. & maria-preta \\
Burseraceae & Commiphora leptophloeos (Mart.) Gillett & catingueira \\
Caesalpinaceae & Caesalpinia pyramidalis Tul. & mororó \\
Caesalpinaceae & Bauhinia cheilantha (Bong.) Steud. & feijão-bravo \\
Capparaceae & Capparisflexuosa L. & mofumbo \\
Combretaceae & Combretum leprosum Mart. & rompe-gibão \\
Erythroxylaceae & Erythroxylum pungens O.E. Schuz & marmeleiro \\
Euphorbiaceae & Croton sonderianus Muell. Arg. & pinhão \\
Euphorbiaceae & Jatropha mollissima (Pohl) Baill & cumaru \\
Fabaceae & Amburana cearensis (Allemão) A.C. Smith & angico \\
Mimosaceae & Anadenanthera colubrina (Vell.) Brenam & jurema-branca \\
Mimosaceae & Pithecellobium foliolosum Benth. & jurema-preta \\
Mimosaceae & Mimosa acutistipula Benth. & \\
\hline
\end{tabular}

(informação pessoal) para cada um dos quatro locais amostrados também na Estação Ecológica do Seridó, que tiveram de 9 a 13 espécies lenhosas arbustivas e arbóreas. Nestes quatro locais, o total de lenhosas foi de 26 espécies e, acrescentando mais o local deste trabalho, o número chega a 27 espécies. Estes números são menores que os da maioria de outras caatingas em todo o Nordeste, tanto as incluídas na revisão de Sampaio (1996) quanto as descritas em trabalhos posteriores (Alcoforado Filho et al. 2003). A baixa riqueza da flora seridoense já havia sido referida por Luetzelburg (1922-1923). Outros trabalhos nas caatingas do Rio Grande do Norte (Tavares et al. 1975; Figueiredo 1987) também têm encontrado baixo número de espécies arbustivas e arbóreas (21 a 34), mesmo amostrando vários locais em mais de um município. Contrastando com estes números, as caatingas dos Agrestes, na borda mais úmida do semi-árido, podem chegar a ter entre 50 e 60 espécies, em um único local (Pereira et al. 2002; Alcoforado Filho et al. 2003). Assim, na escala regional, há nítido efeito da maior disponibilidade hídrica no aumento da riqueza florística.

O número de espécies é influenciado pelo uso prévio da área, com redução forte quando o grau de antropização foi grande (Pereira et al. 2003). Infelizmente, o histórico de uso da vegetação de muitos trabalhos, na caatinga, não foi descrito. É possível que os baixos números de espécies relatados por Tavares et al. (1975), para quatro locais do vale do Piranhas (27 espécies), e por Figueiredo (1987), para oito municípios da região salineira (34 espécies), sejam explicados, pelo menos em parte, pela antropização.
Como a vegetação da Estação vem sendo bem preservada há pelo menos 20 anos, a baixa riqueza não é resultado de perturbações recentes e, se foi influenciada por antropismo, o efeito estaria presente depois de mais de duas décadas. Também no trabalho de dissertação de mestrado de Rinaldo Ferreira, defendida em Viçosa em 1988 (informação pessoal), feito em Açu, o baixo número de espécies (21) não deve ser atribuído a perturbações antrópicas já que a vegetação da área vinha sendo preservada pelo menos desde 1944.

De acordo com o baixo número de espécies, a riqueza e a diversidade foram baixas: 1,86 esp.1n.ind. ${ }^{-1}$ (ln ind.) $)^{-1}$ e 1,939 nats.ind. ${ }^{-1}$. São valores mais baixos que os da maioria das caatingas de outros Estados da região (Sampaio 1996).

Estes resultados parecem indicar que a caatinga de muitas partes do Rio Grande do Norte é mais pobre em espécies que as de outros Estados. Entretanto, os locais amostrados foram poucos para permitir conclusões seguras. A baixa disponibilidade hídrica deve ser uma das causas da baixa pobreza mas a comparação com os locais descritos em outros trabalhos é dificultada porque, em geral, a única variável relacionada com esta disponibilidade que é apresentada é o total pluviométrico anual e a disponibilidade também é afetada pela distribuição das chuvas ao longo do ano e pela capacidade de retenção de umidade dos solos (Sampaio 2003). Há locais com precipitação anual semelhante à do Seridó e maior número de espécies (Sampaio 1996), mas talvez não tenham distribuição das chuvas tão má e solos tão rasos e pedregosos. 
Chama a atenção a ausência de espécies de Cactaceae de maior porte, embora tenham sido encontradas por Camacho (informação pessoal) em outros locais da Estação. Em geral, é uma família presente em locais de caatinga (Rodal et al. 1999; Alcoforado Filho et al. 2003), principalmente os de baixa pluviosidade como os do Seridó.

Estrutura da comunidade - A comunidade apresentou fisionomia bastante aberta. A densidade encontrada foi de 3.250 indivíduos por hectare, incluindo todas as plantas com diâmetro a 1,30 m de altura do solo (DAP) igual ou superior a $1 \mathrm{~cm}$ (Tab. 2). Usando um critério um pouco mais abrangente $(\geq 1 \mathrm{~cm}$ diâm. ao nível do solo, DNS), em 16 locais do Seridó, Costa et al. (2002) encontraram densidades semelhantes ou maiores em 6 deles (3.050 a 4.220 plantas ha ${ }^{-1}$ ) e bem menores nos outros 10 locais (360 a 2.290 plantas ha ${ }^{-1}$ ). A ausência de descrição mais detalhada destes locais, acrescida da informação de que alguns eram degradados, impede discussão mais aprofundada. Entretanto, parecem valores baixos, comparados aos de outros locais de caatinga (Sampaio 1996), exceto de alguns cuja baixa densidade ocorria junto com um número relativamente alto de plantas de diâmetros do caule e alturas totais grandes (Alcoforado Filho et al. 2003).

Como a maior parte dos levantamentos já feitos usou critérios mais exclusivos que o presente trabalho, para comparar as densidades é preciso eliminar do cálculo as plantas menores. Recalculando para o critério mais usado nos trabalhos em caatinga ( $\geq 3 \mathrm{~cm}$ diâm. ao nível do solo, DNS), a densidade foi de 2.258 ind.ha $^{-1}$. Cálculos semelhantes foram feitos considerando os outros critérios já usados em outros trabalhos (principalmente DAP $\geq 5 \mathrm{~cm}$ ). Usando quaisquer dos critérios, a densidade deste local da Estação foi mais baixa que a de quase todas as outras áreas de caatinga (Sampaio 1996). Foi também um pouco mais baixa que a encontrada por Camacho (informação pessoal), em um dos quatro locais que este autor amostrou (2.812 plantas $\mathrm{ha}^{-1}$ ) na própria Estação, mas bem menor que a dos outros três locais (4.120 a 7.015 plantas ha-1).

A comunidade da Estação teve diâmetros e alturas médios de $4,0 \mathrm{~cm}$ e 3,4 m, respectivamente. São valores baixos, mas a comparação com outros locais é complicada porque estas médias são muito influenciadas pelo critério de inclusão de plantas e, neste trabalho, foram incluídas plantas menores que na maioria dos trabalhos já publicados. A Estação teve poucas plantas de diâmetros e alturas grandes (Fig. 1), comparada a outros locais de caatinga. Apenas 10 plantas no hectare amostrado tiveram diâmetro maior que $27 \mathrm{~cm}$ e apenas 200 plantas maior que $12 \mathrm{~cm}$. São números mais baixos que todos os compilados da literatura sobre caatinga por Alcoforado Filho et al. (2003). Apenas duas plantas tiveram mais de $8 \mathrm{~m}$ alt., também os números mais baixos entre os locais registrados pelos autores acima, exceto por 2 locais

Tabela 2. Variáveis fitossociológicas das espécies da Estação Ecológica do Seridó, Serra Negra do Norte, RN, Brasil. (D = Densidade; $\mathrm{F}=$ freqüência absoluta; $\mathrm{AB}=$ área basal; $\mathrm{IVI}=$ índice de valor de importância; $\mathrm{B}=$ biomasssa aérea; $\mathrm{AC}=$ área de copa; Hmax. $=$ altura máxima e Dmax. = diâmetro máximo).

\begin{tabular}{|c|c|c|c|c|c|c|c|c|}
\hline Espécie & $\begin{array}{c}\mathrm{D} \\
\text { ind.ha } \\
\mathrm{a}^{-1}\end{array}$ & $\begin{array}{c}\text { FA } \\
\%\end{array}$ & $\begin{array}{c}\mathrm{AB} \\
\mathrm{cm}^{2} \mathrm{ha}^{-1}\end{array}$ & IVI & $\begin{array}{c}\text { B } \\
\mathrm{kg} \mathrm{ha}^{-1}\end{array}$ & $\begin{array}{c}\mathrm{AC} \\
\mathrm{m}^{2} \mathrm{ha}^{-1}\end{array}$ & $\begin{array}{l}\text { Hmax. } \\
\text { m }\end{array}$ & $\begin{array}{c}\text { Dmax. } \\
\mathrm{cm}\end{array}$ \\
\hline Aspidosperma pyrifolium & 1.199 & 100 & 30.675 & 101,8 & 13.259 & 3.554 & 9,5 & 36,9 \\
\hline Pithecellobium foliolosum & 562 & 91 & 8.255 & 44,3 & 3.086 & 1.474 & 8,6 & 15,2 \\
\hline Mimosa acutistipula & 287 & 72 & 6.935 & 30,8 & 2.847 & 1.209 & 6,0 & 20,9 \\
\hline Croton sonderianus & 452 & 78 & 3.064 & 30,5 & 1.003 & 472 & 5,3 & 9,8 \\
\hline Caesalpinia pyramidalis & 202 & 49 & 5.450 & 22,4 & 2.302 & 710 & 7,0 & 19,7 \\
\hline Combretum leprosum & 120 & 52 & 2.321 & 15,2 & 903 & 470 & 6,5 & 12,8 \\
\hline Anadenanthera colubrina & 123 & 60 & 993 & 14,3 & 360 & 176 & 6,0 & 11,1 \\
\hline Jatropha mollissima & 103 & 59 & 1.147 & 13,8 & 395 & 142 & 6,0 & 8,9 \\
\hline Capparis flexuosa & 85 & 53 & 920 & 12,0 & 368 & 208 & 5,5 & 17,8 \\
\hline Erythroxylum pungens & 77 & 39 & 918 & 9,6 & 337 & 176 & 5,2 & 11,1 \\
\hline Tabebuia impetiginosa & 12 & 12 & 316 & 2,7 & 131 & 62 & 5,0 & 12,7 \\
\hline Cordia globosa & 6 & 5 & 35 & 1,0 & 11 & 8 & 3,4 & 4,7 \\
\hline Bauhinia cheilantha & 15 & 2 & 80 & 0,9 & 26 & 41 & 3,8 & 4,7 \\
\hline Amburana cearensis & 2 & 2 & 91 & 0,5 & 39 & 16 & 4,7 & 10,2 \\
\hline Commiphora leptophloeos & 2 & 2 & 10 & 0,4 & 3 & 7 & 3,6 & 3,2 \\
\hline Total & 3.247 & 676 & 61.210 & 300 & 25.070 & 8.723 & - & - \\
\hline
\end{tabular}


620 Amorim, Sampaio \& Araújo: Flora e estrutura da vegetação arbustivo-arbórea de uma área de caatinga do Seridó...

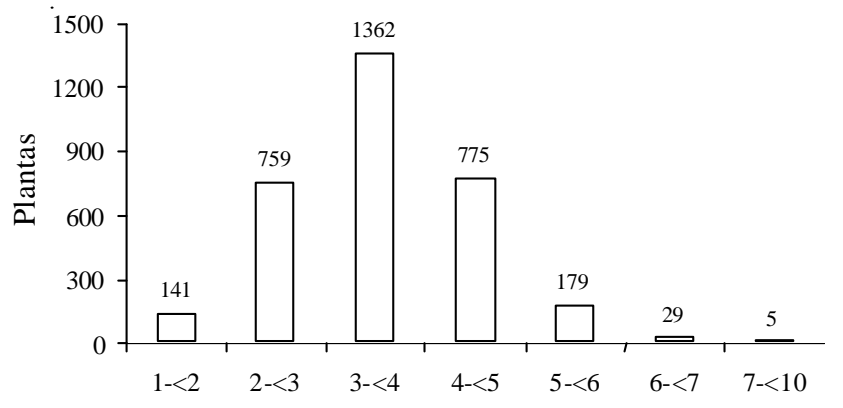

Classes de altura $(\mathrm{m})$

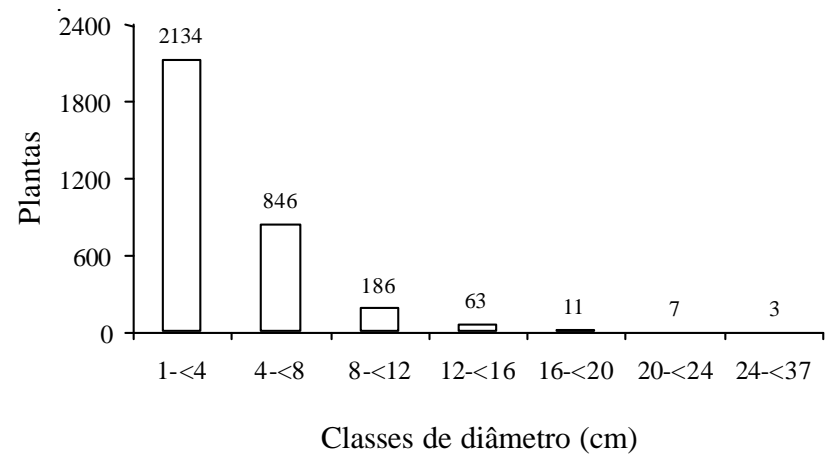

Figura 1. Distribuição das plantas amostradas na Estação Ecológica do Seridó, Serra Negra do Norte, RN, Brasil, em classes de altura e de diâmetro.

entre os 11 referidos. Os maiores valores de diâmetro e altura, alcançados por um pereiro (Aspidosperma pyrifolium), foram apenas de $37 \mathrm{~cm}$ e $9,5 \mathrm{~m}$, também mais baixos que os da maioria das caatingas.

Consistente com a baixa densidade e os baixos diâmetros, a área basal total $\left(6,1 \mathrm{~m}^{2} \mathrm{ha}^{-1}\right)$ foi uma das menores já reportadas, incluindo as de várias áreas sem o histórico de preservação da Estação. Valores na mesma ordem de grandeza (até $10 \mathrm{~m}^{2} \mathrm{ha}^{-1}$ ) só foram reportados para um local em Santa Maria da Boa Vista, PE (Drumond et al. 1982), e para dois locais do Rio Grande do Norte, sendo um também no Seridó (Tavares et al. 1975) e o outro na reserva de Açu, com várias décadas de preservação (Ferreira, informação pessoal). Nos outros locais da Estação amostrados por Camacho (informação pessoal), as áreas basais foram um pouco maiores $(9,98$ a $18,92 \mathrm{~m}^{2} . \mathrm{ha}^{-1}$ ) que as deste trabalho, embora ainda pequenas em relação a locais de caatinga pouco antropizada de outros Estados. Todas estas variáveis apontam para o baixo porte da vegetação da Estação mas não transmitem uma idéia muito clara da ocupação do espaço.

A soma da área de projeção das copas de todos os indivíduos foi de $8.723 \mathrm{~m}^{2}$.ha-1. Assim, pelo menos
$13 \%$ da área não era coberta por nenhuma copa. $\mathrm{Na}$ verdade, a área descoberta era maior porque há sempre alguma sobreposição das copas medidas. Entre as 100 parcelas do trabalho, 21 tiveram áreas de copa maiores que as do terreno, ou seja, mais de $100 \%$ de cobertura (máximo de $21.100 \mathrm{~m}^{2} \cdot \mathrm{ha}^{-1}$ ), enquanto as menores coberturas foram de cerca de $40 \%$. Há apenas um trabalho com medidas de copas, na caatinga, para comparar com estas: o de Albuquerque et al. (1982), em Petrolina, PE, que encontrou $30.070 \mathrm{~m}^{2} . \mathrm{ha}^{-1}$, somando as copas das árvores e dos arbustos. $\mathrm{O}$ fato da caatinga de Petrolina ter porte relativamente baixo e mesmo assim ter uma cobertura de copas tão maior que a da Estação ajuda a imaginar a ocupação na nesta, com muitos espaços abertos, apenas recobertos pelo manto de herbáceas, com uma aparência que lembra a do cerrado stricto sensu (Goodland \& Ferri 1979).

Os baixos valores de densidade, área basal, altura e área das copas da Estação indicam que suas plantas não ocupam todo o espaço disponível e que têm porte relativamente pequeno. As estimativas de biomassa (Tab. 2), tanto usando apenas os diâmetros dos caules

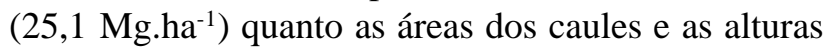

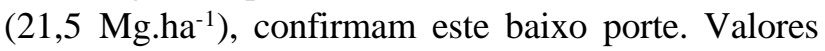

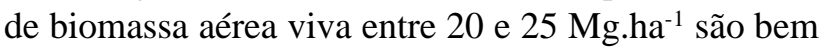
mais baixos que os $74 \mathrm{Mg} \cdot \mathrm{ha}^{-1}$ determinados em caatinga de Serra Talhada, PE (Kauffman et al. 1993). Também foram mais baixos que os estimados na tese de Silva (informação pessoal) para todos os outros locais de caatinga referidos como pouco antropizados

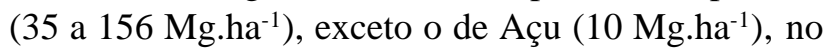
Rio Grande do Norte (Ferreira, informação pessoal). Das estimativas dos 16 locais do Seridó (Costa et al.

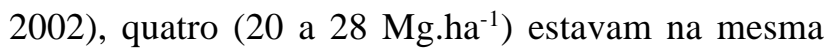
faixa estimada para a Estação Ecológica do Seridó e apenas uma (45 Mg.ha-1) foi bem maior, enquanto oito outras não passaram de $10 \mathrm{Mg} \cdot \mathrm{ha}^{-1}$ e três de $17 \mathrm{Mg} \cdot \mathrm{ha}^{-1}$. Todos estes valores indicam que a região do Seridó possui uma vegetação de caatinga aberta e de baixa biomassa, não sendo isto atribuído a fatores antrópicos. Confirma-se a hipótese de que o tipo de caatinga da região do Seridó difere quanto à estrutura da vegetação dos demais tipos regionais de caatinga.

A relação das alturas e áreas de copa em função dos diâmetros do caule resultaram em equações com parâmetros não muito diferentes dos obtidos por E.V.S.B. Sampaio \& G.C. Silva (dados não publicados) e com coeficientes de determinação significativos, embora não tão altos quanto os obtidos por eles. A equação para alturas e diâmetros foi $\mathrm{H}_{\mathrm{n}}=2,2327$ $\operatorname{DAP}_{\mathrm{cm}}{ }^{0,3172}$, com $\mathrm{R}^{2}=0,42$, contrastando com 
$\mathrm{H}_{\mathrm{m}}=2,0175 \mathrm{DAP}_{\mathrm{cm}}{ }^{0,4308}$, com $\mathrm{R}^{2}=0,59$, daqueles autores. A equação para áreas de copa e diâmetros foi $\mathrm{AC}_{\mathrm{m} 2}=0,2523 \mathrm{DAP}_{\mathrm{cm}}{ }^{1,5095}$, com $\mathrm{R}^{2}=0,70$, contrastando com $\mathrm{AC}_{\mathrm{m} 2}=0,3621 \mathrm{DAP}_{\mathrm{cm}}{ }^{1,5763}$, com $\mathrm{R}^{2}=0,73$, do trabalho citado. É interessante registrar que áreas de copa também poderiam ser estimadas em função dos diâmetros com uma equação linear, passando pela origem $\left(\mathrm{AC}_{\mathrm{m} 2}=0,83 \mathrm{DAP}_{\mathrm{cm}}\right)$, sem muita perda da determinação $\left(R^{2}=0,66\right)$, o que facilita bastante estimativas rápidas. Os valores um pouco mais baixos dos expoentes das equações da Estação significam que as plantas deste local têm áreas de copa e, principalmente, alturas menores que as do trabalho de E.V.S.B. Sampaio \& G.C. Silva (dados não publicados), para os mesmos diâmetros do caule. Estas diferenças em altura explicam, em parte, porque a estimativa da biomassa da vegetação da Estação é menor quando feita através da equação com área basal e altura do que quando feita apenas com o diâmetro. $\mathrm{O}$ desenvolvimento de equações como estas, em trabalhos futuros, permitirá que se estime melhor a estrutura da vegetação da caatinga a partir de apenas algumas das variáveis possíveis, provavelmente as de mais fácil obtenção, viabilizando um maior acúmulo de dados e um melhor conhecimento da variabilidade de situações.

Análise de populações - A vegetação deste local da Estação Ecológica do Seridó é dominada por Aspidosperma pyrifolium (pereiro), que correspondeu a $37 \%$ da densidade, $50 \%$ da área basal, 34\% do IVI, $53 \%$ da biomassa e $41 \%$ da área total de copas (Tab. 2). O pereiro é uma espécie comum em muitas áreas de caatinga mas em poucas delas chega a ser a espécie com maior dominância. Junto com outras espécies, entra na lista de dominantes de três dos seis tipos de vegetação de caatinga, definidos por Andrade-Lima (1981). Nos dois tipos que ocupam as maiores áreas e que foram subdivididos em quatro subtipos cada um, entra na caracterização (feita pelos gêneros, mas onde a espécie é o elemento chave) de um dos subtipos do tipo II (Caesalpinia - Spondias - Bursera Aspidosperma) e em três subtipos do tipo IV (Caesalpinia - Aspidosperma - Jatropha; Caesalpinia - Aspidosperma; e Aspidosperma Pilosocereus). Curiosamente, o único subtipo que foi localizado por Andrade-Lima (1981) especificamente no Seridó, em áreas abertas, de solos rasos e com plantas atrofiadas e esparsas, não inclui Aspidosperma (Mimosa - Caesalpinia - Aristida). A área amostrada deve pertencer a este último subtipo, pela localização, pela descrição e pela presença de espécies que caracterizam os outros gêneros. Neste local específico, Aspidosperma deveria encabeçar a descrição, mas a variação de local a local é grande, como mostram os dados de Camacho (informação pessoal) para outros quatro locais da Estação. Em apenas um deles pereiro foi a espécie dominante e em um outro ficou entre as três espécies principais, não se destacando nos outros dois locais.

Na revisão de Sampaio (1996), Aspidosperma pyrifolium aparece como uma das seis espécies de maior densidade, área basal ou volume de madeira em 27 de 59 locais amostrados mas só em um deles destacou-se como o mais dominante. Neste local, um dos quatro da tese de M.J.N. Rodal, defendida na UNICAMP em 1992 (informação pessoal), o solo tinha a textura mais argilosa, o maior $\mathrm{pH}$ e os maiores teores de Ca e P. Em outros trabalhos, o pereiro destacou-se principalmente em locais de Vertissolo, quando a amostragem foi feita separando por tipo de solo (Santos et al. 1992). Na amostragem em Pendência, RN, Fotius \& Sá (1988) também encontraram o pereiro dominando em dois locais de Vertissolo, concluindo que nestes solos as plantas dominantes foram $A$. pyrifolium, Combretum leprosum e Aristida elliptica. Assim, parece que o pereiro predomina em local de baixa precipitação e solos pesados (com teores altos de argila do tipo 2:1), com pH de neutro para alcalino e teores altos de nutrientes.

Depois do Aspidosperma pyrifolium, as espécies de maior dominância (Tab. 2) foram Pithecellobium foliolosum (jurema branca), Mimosa acutistipula (jurema preta), Croton sonderianus (marmeleiro) e Caesalpinia pyramidalis (catingueira). Juntas respondem por mais de $80 \%$ da densidade, da área basal e de copas e da biomassa aérea, confirmando um padrão repetidas vezes observado na caatinga, de concentração em poucas espécies (Sampaio 1996). Exceto pela jurema branca, são das espécies mais comuns e mais importantes nos levantamentos de caatingas sobre o cristalino (Sampaio 1996). A jurema branca, embora seja encontrada em muitos levantamentos, quase nunca tem destaque entre as espécies mais importantes. Caesalpinia pyramidalis e Croton sonderianus foram as espécies dominantes nos outros locais da Estação amostrados por Camacho (informação pessoal).

Das arbóreas de grande porte da caatinga, estiveram presentes Anadenanthera colubrina, Tabebeuia impetiginosa, Amburana cearensis e Commiphora leptophloeos. Nenhuma delas teve indivíduos de maior porte que alguns dos pereiros (Tab. 2) e todas tiveram os DAP máximos e as alturas 
máximas inferiores aos encontrados em outros locais de caatinga. As condições ambientais não devem ser favoráveis ao crescimento destas espécies ou ter-se-ia de admitir que elas só se estabeleceram, no local, depois que a Estação foi criada. Caso já estivessem no local há mais de 20 anos, as taxas de crescimento devem ter sido muito baixas. Na Estação, há indivíduos destas espécies com maiores diâmetros mas não se sabe sua idade. A maior parte dos indivíduos destas espécies amostrados por Camacho (informação pessoal) também era de diâmetros pequenos, embora ele tenha encontrado plantas maiores de umburana e de angico. A maior delas era uma umburana de cerca de $8 \mathrm{~m}$ de altura e de $60 \mathrm{~cm}$ de diâmetro.

Pode-se concluir que a flora da Estação Ecológica do Seridó tem um número de espécies menor que os das áreas de caatinga já pesquisadas em outras regiões e que todas as espécies presentes são comuns na flora da caatinga sobre o cristalino dessas outras regiões. Portanto, quanto à flora, a vegetação do Seridó parece um subconjunto empobrecido da flora geral da caatinga do cristalino. Quanto à estrutura, a vegetação lenhosa do Seridó é mais aberta, mais baixa e com menor biomassa que as das outras áreas de caatinga. Confirma-se que a vegetação do Seridó constitui um tipo de fisionomia de caatinga distinto dos demais

\section{Agradecimentos}

Ao IBAMA, na pessoa do chefe da Estação Ecológica do Seridó, Adson Borges Macêdo; ao InterAmerican Institute for Global Change Research, pelo apoio; ao $\mathrm{CNPq}$, pelas bolsas concedidas.

\section{Referências bibliográficas}

Albuquerque, S.G.; Soares, J.G.G. \& Araújo Filho, J.A. 1982. Densidade de espécies arbustivas em vegetação de caatinga. Petrolina, EMBRAPA-CPATSA. (Pesquisa em andamento, 16).

Alcoforado Filho, F.G.; Sampaio, E.V.S.B. \& Rodal, M.J.N. 2003. Florística e fitossociologia de um remanescente de vegetação caducifólia arbórea em Caruaru, Pernambuco. Acta Botanica Brasilica 17(2): 287-303.

Andrade-Lima, D. 1981. The caatinga dominium. Revista Brasileira de Botânica 4: 149-153.

Costa, T.C.C.; Accioly, L.J.O.; Oliveira, M.A.J.; Burgos, N. \& Silva, F.H.B.B. 2002. Phytomass mapping of the "Seridó caatinga" vegetation by the plant area and the normalized difference vegetation indeces. Scientia Agricola 59: 707-715.
Araújo, E.L. \& Ferraz, E.M.N. 2004. Amostragem da vegetação e índices de diversidade. Pp. 89-137. In: U.P. Albuquerque \& R.F.P. Lucena (eds.). Métodos e Técnicas na pesquisa etnobotânica. Recife, Livro Rápido.

Drumond, M.A.; Lima, P.C.F.; Souza, S.M. \& Lima, J.L.S. 1982. Sociabilidade das espécies florestais de caatinga em Santa Maria da Boa Vista - PE. Boletim de Pesquisa Florestal 4: 47-59.

Embrapa. 1999. Sistema brasileiro de classificação de solos . Rio de Janeiro, EMBRAPA, Centro Nacional de Pesquisas de Solos.

Fotius, A. \& Sá, I.B. 1988. Prospecção botânica em área de exploração petrolífera, no município de Pendências, RN. Petrolina, CPATSA. (Documentos 47)

Figueiredo, M.A. 1987. A microrregião salineira norteriograndense no domínio das caatingas. Mossoró, Escola Superior de Agricultura de Mossoró. (Coleção Mossoroense, 353).

Goodland, R. \& Ferri, M.G. 1979. Ecologia do Cerrado. São Paulo, Editora da Universidade de São Paulo.

Kauffman J.B.; Sanford, R.L.; Cummings, D.L.; Salcedo, I.H.\& Sampaio, E.V.S.B. 1993. Biomass and nutrient dynamics associated with slash fires in neotropical dry forests. Ecology 74: 140-151.

Luetzelburg, P. 1922-23. Estudo botânico do Nordeste. Rio de Janeiro, Inspetoria de Obras Contra as Secas.

Ministério da Agricultura. 1971. Levantamento exploratório - reconhecimento de solos do Estado do Rio Grande do Norte. Recife, Ministério da Agricultura.

Ministério do Meio Ambiente. 2004. Biodiversidade da caatinga: áreas e ações prioritárias para a conservação. Brasília, Ministério do Meio Ambiente e Universidade Federal de Pernambuco.

Mueller-Dombois, D. \& Ellemberg, H. 1974. Aims and methods of vegetation ecology. New York, John Wiley \& Sons.

Pereira, I.M.; Andrade, L.A.; Barbosa, M.R.V. \& Sampaio, E.V.S.B. 2002. Composição florística e análise fitossociológica do componente lenhoso de um remanescente de caatinga no Agreste Paraíbano. Acta Botanica Brasilica 16(3): 357-369.

Pereira, I.M.; Andrade, L.A.; Sampaio, E.V.S.B. \& Barbosa, M.R.V. 2003. Use-history effects on structure and flora of caatinga. Biotropica 35(2): 154-165.

Rodal, M.J.N.; Nascimento, L.M. \& Melo, A.L. 1999. Composição florística de um trecho de vegetação arbustiva caducifólia, no município de Ibimirim, Pernambuco, Brasil. Acta Botanica Brasilica 13(1): 15-28.

Rodal, M.J.N.; Sampaio, E.V.S.B. \& Figueiredo, M.A. 1992. Manual sobre métodos de estudo florístico e fitossociológico - ecossistema caatinga. Brasília, Sociedade Botânica do Brasil.

Sampaio, E.V.S.B. 1996. Fitossociologia. Pp. 203-224. In: E.V.S.B. Sampaio; S.J. Mayo \& M.R.V. Barbosa (eds.). Pesquisa botânica nordestina: progresso e perspectivas. Recife, Sociedade Botânica do Brasil. 
Sampaio, E.V.S.B. 2003. Caracterização da caatinga e fatores ambientais que afetam a ecologia das plantas lenhosas. Pp. 129-142. In: V.C. Sales (ed.). Ecossistemas brasileiros: manejo e conservação. Fortaleza, Expressão Gráfica e Editora.

Sampaio, E.V.S.B.; Sampaio, Y.; Vital, T.; Araújo, M.S.B. \& Sampaio, G.R. 2003. Desertificação no Brasil. Recife, Ed. Universitária UFPE.

Santos, M.F.A.V.; Ribeiro, M.R. \& Sampaio, E.V.S.B. 1992. Semelhanças vegetacionais em sete solos da caatinga. Pesquisa Agropecuária Brasileira 27: 305-314.
Shepherd, G.J. 1995. FITOPAC 1. Manual do usuário. Campinas, Universidade de Campinas, Departamento de Botânica.

Tavares, S.; Paiva, F.A.V.; Tavares, E.J.S. \& Carvalho, G.H. 1975. Inventário florestal da Paraíba e no Rio Grande do Norte l. Estudo preliminar das matas remanescentes do vale do Piranhas. Recife, SUDENE. (Recursos Naturais, 3).

Whittaker, R.H. 1975. Communities and ecosystems. New York, MacMillan. 